\title{
As noites e a estrada do sol
}

\section{Ney Costa Santos}

Dolores Duran era a grande crooner das boates de Copacabana nos anos1950. Little Club, Vogue, Cangaceiro eram alguns dos lugares em que cantava com elegância música brasileira e internacional. Com um estilo de canto influenciado e contemporâneo às damas do jazz e da grande canção americana, Dolores era capaz de passar pela sofisticação de My Funny Valentine ou de um scat singing à maneira de Ella Fitzgerald, para um samba carioca de Billy Blanco ou uma toada nordestina de Chico Anísio. Foi uma cantora excepcional e, de certa forma, em seu modo de cantar já havia o estilo que seria consagrado na Bossa Nova. Nada de berreiros ou cantos operísticos e sim suavidade na emissão vocal, atenção às harmonias e à sonoridade do que se cantava.Certamente teria sido uma grande cantora de Bossa Nova se não houvesse morrido aos 29 anos, em outubro de 1959.

Dolores Duran deixou uma obra com 35 músicas de qualidade sendo, até hoje, a mais gravada entre as compositoras brasileiras.

Embora os seus contemporâneos afirmassem que era uma mulher alegre, inteligente e amiga, os temas de suas canções eram quase sempre as dores de amor. Podiam oscilar entre a ironia e o humor leve, como em Fim de Caso e Ideias Erradas, mas, em geral, as letras das músicas eram sobre solidão, perda, procura e, principalmente, espera.

Eu desconfio

Que o nosso caso está na hora de acabar

Há um adeus em cada gesto, em cada olhar 
Mas nós não temos é coragem de falar.

Nós já tivemos

A nossa fase de carinho apaixonado

De fazer versos, de viver sempre abraçados

Naquela base do só vou se você for

Mas de repente

Fomos ficando cada dia mais sozinhos

Embora juntos, cada qual tem seu caminho

Mas nós não temos é coragem de brigar.

Tenho pensado

E Deus permita que eu esteja errada

Mas eu estou, ah eu estou desconfiada

Que o nosso caso está na hora de acabar.

Suavidade e singeleza na melodia e na letra, ambas de sua autoria, na observação delicada do desgaste da relação amorosa no cotidiano, sem dramas e descabelamentos, uma constatação sensível da fugacidade das paixões. Dolores gravou essa musica bem ao seu estilo, elegante, com um lindo scat antes da repetição do final da letra.

Em Ideias Erradas, Dolores lembra ao homem que sua dedicação à relação não significa dependência e submissão. Ela mantém sua autonomia e se tudo acabar, paciência. Ela aceitará, sofrerá,mas a vida seguirá seu rumo.A música é de autoria de um de seus parceiros mais constantes, o pianista Ribamar, e a gravação de Dolores já tem um clima bem pré Bossa Nova.

Não faça ideias erradas de mim

Só porque eu quero você tanto assim

Eu gosto de você, mas não esqueço

De tudo quanto valho e mereço

Não pense que se você me deixar

A dor será capaz de me matar

Um verdadeiro amor não se aproveita

Se não se faz senão aquilo que enobrece

Depois que ele se vai a gente aceita

A gente bebe, a gente chora, mas esquece.

Embora cantasse todo tipo de musica, Dolores Duran ficou mais conhecida como cantora da noite, das desilusões amorosas, da manifestação dos desejos femininos entre valores rígidos e a modernidade comportamental daquele trecho da

92 ALCEU - v. 18 - n. 36 - p. 91 a 102 - jan-jun./2018 
zona sul carioca. É a música do cotidiano de busca e espera do amor. Em Noite de Paz, cansada e varada de angustia, ela pede a Deus que lhe dê uma noite comum, uma noite em que simplesmente pudesse dormir e descansar.

\author{
Dai-me, Senhor \\ Uma noite sem pensar \\ Dai-me Senhor \\ Uma noite bem comum \\ Uma só noite em que possa descansar \\ Sem esperança e sem sonho nenhum \\ Por uma só noite assim posso trocar \\ O que eu tiver de mais puro e mais sincero \\ Uma só noite de paz prá não lembrar \\ Que eu não devia esperar e ainda espero
}

Em $A$ Noite do Meu Bem, a mais conhecida de suas composições, autora de letra e música, ela se prepara para receber o seu amado; dará a ele tudo que de mais belo possa para enfeitar aquela noite, mas, ao final, depois de tanta espera, ela percebe que, talvez, pela demora da chegada, já não esteja mais pronta, talvez seja tarde demais, não seja mais possível dar a ele tudo que desejara. Há nessa música algo que lembra o célebre poema Noite Escura, de São João da Cruz, em que a alma aguarda e se prepara para o encontro com o seu amado. Embora o poema seja de júbilo pelo encontro com Deus, há algo que se lhe assemelha no movimento de preparo da alma para esse encontro. Também no Cântico dos Cânticos há preparação para o encontro com a amada, a promessa de dar a ela o que de mais belo houver no mundo. Em Dolores, na Noite do meu Bem, não há misticismo. Suas dores, anseios e inquietações são cruamente humanas, mas a noite em que espera não se parece mais com aquelas dos bares e boates mas, sim, com a "noite antiquíssima e idêntica" de que nos fala Fernando Pessoa. Por triste ironia Dolores gravou essa música poucos meses antes de sua morte.

Hoje eu quero a rosa mais linda que houver

E a primeira estrela que vier

Para enfeitar a noite do meu bem

Hoje eu quero paz de criança dormindo

E o abandono de flores se abrindo

Para enfeitar a noite do meu bem

Quero a alegria de um barco voltando

Quero ternura de mãos se encontrando

Para enfeitar a noite do meu bem

Ah, eu quero o amor, o amor mais profundo 
Eu quero toda beleza do mundo

Para enfeitar a noite do meu bem

Quero a alegria de um barco voltando

Quero ternura de mãos se encontrando

Para enfeitar a noite do meu bem

Ah, como esse bem demorou a chegar

E eu já nem sei se terei no olhar

Toda pureza que eu quero lhe dar

No ambiente enfumaçado das boates, Dolores se debruça sobre o Mistério e vive a sua noite da busca, de dentro do deserto da boemia sem fim. Sabedora de que tinha sérios problemas cardíacos que poderiam abreviar sua vida, ela tinha pressa e vivia tudo com intensidade. Suas paixões eram ardentes e como tal se consumiam, mas entre as cinzas ela continuava esperando seu amado chegar.

O núcleo, o ambiente da Noite do Meu Bem, é a preparação de alguém para a chegada do amor definitivo, de alguém que ela não devia mais esperar, mas ainda esperava; alguém que quando chegasse talvez ela não estivesse mais pronta para a entrega. E a noite real vira a noite mítica, a noite das bodas místicas de encontro e entrega.

Em uma noite escura, com ânsias, em amores inflamada, oh ditosa ventura!, saí sem notada, estando minha casa sossegada.

$\mathrm{Na}$ escuridão, segura, pela secreta escada disfarçada, oh ditosa ventura!, no escuro, ocultada, estando minha casa sossegada.

Nessa noite ditosa, secretamente, que ninguém me via, de nada curiosa, sem outra luz nem guia senão a que no coração me ardia.

Só esta me guiava com mais certeza que a luz do meio-dia, 
aonde me esperava

quem eu bem conhecia,

num sítio onde ninguém aparecia.

Tanto quanto São João da Cruz, Dolores também está ansiosa e se deixa guiar pelo coração, mas ao contrário de João, que conhece o seu amor e sabe onde ele está e que desse lugar ninguém mais surgiria, Dolores procura e espera pelo amor que a apaziguará e a completará. Dolores anseia pela fusão com o amor, mas busca e espera e enquanto ele não chega, enfeita a noite do encontro, a noite de seu bem.

Noite, que me guiaste!

Oh noite mais amável que a alvorada!

Oh noite que juntaste

Amado com amada, amada em seu Amado transformada!

Em seu peito florido, que só para ele inteiro se guardava, ficou adormecido, e eu o afagava e o leque de cedros brisa dava.

A viração amena, enquanto eu seus cabelos espargia, com sua mão serena

o meu colo feria

e meus sentidos todos suspendia.

Detive-me, olvidei-me,

o rosto reclinei sobre o Amado, cessou tudo e deixei-me, deixando o meu cuidado por entre as açucenas olvidado.

Enquanto João da Cruz diz que esses versos são "canções da alma que se rejubila por ter chegado ao alto estado da perfeição, que é a união com Deus, pelo caminho da negação espiritual", Dolores, mais humana, constata que apesar de todo o seu preparo e de também ter sido guiada pelo coração, pela demora de seu bem, duvida se será possível o encontro. Os versos de João da Cruz são de júbilo pela união mística da alma com seu criador; os de Dolores são de dúvida e melancolia em relação ao seu encontro tão humano, movimento pendular de erotismo e espiritualidade. 
Se em João da Cruz, na Noite Escura, há a união de Amado com amada, amada em Amado transformada, em Dolores a noite não lhe traz nenhuma certeza e talvez por isso, sabedora disso, tenha querido da Noite apenas e humanamente que ela lhe trouxesse o sono e o descanso. A Noite não lhe trouxe a liberdade, nem o encontro, nem o êxtase. O que a libertará será a Estrada do Sol quando sua poesia encontra as harmonias debussyanas de Tom Jobim.

\author{
É de manhã \\ Vem o sol, mas os pingos da chuva \\ Que ontem caiu \\ Ainda estão a brilhar, ainda estão a dançar \\ Ao vento alegre que me traz essa canção \\ Quero que você me dê a mão \\ Vamos sair por aí \\ Sem pensar no que foi que sonhei, \\ Que chorei, que sofri \\ Pois a nossa manhã \\ Já me fez esquecer \\ Me dê a mão vamos sair prá ver o sol
}

Diante daquela luz, não mais importava o que se havia sonhado, sofrido chorado; o que agora importava era que depois de tanto esperar, o amor estava agora ao seu lado, ela podia pegar a sua mão e saírem simplesmente para ver o sol que cintilava nas gotinhas que restavam da chuva da madrugada.

Dolores Duran se libertou das amarguras da noite caminhando de mãos dadas com Tom Jobim na Estrada do Sol. Toda a intensa e triste beleza de sua produção é noturna e fala da procura e da perda do amor. Se na Noite do Meu Bem ela se preparou para dar tudo de melhor e mais belo que pudesse oferecer ao amado e ele demorou a chegar, é tão somente na Estrada do Sol, a única música diurna e solar de sua obra, que ela se desprende de si e do seu tempo.

Dolores não encontrou, nem era seu objetivo, o êxtase místico de João da Cruz, mas, sim, encontrou algo de outro tipo, uma epifania, em que o Mistério se revela no comum, nas coisas poucas e pequenas, no sol que nasce todos os dias e nos convida a caminhar pela estrada iluminada por sua luz.

A maioria de suas composições mostra o conflito de uma mulher que tinha um comportamento livre, que trabalhava, era dona do seu nariz, mas que trazia em si os valores passivos atribuídos ainda à mulher de seu tempo. Aquela que era submissa, que esperava o seu homem, aquele alguém que iria trazer paz e completude para sua vida. Dolores é uma mulher dos anos 50 na noite de Copacabana. Suas músicas estão envolvidas em clima de busca e espera. Só Estrada do Sol está além de sua época. Não há nela nada que, ao ouvirmos qualquer uma de suas muitas gravações, nos 
lancemos de volta aos anos 50. Nessa canção, a letra de Dolores é afirmativa, quase imperativa. Ela pega na mão do amado e caminha. E não mais importa o passado. Dolores segue na luz das harmonias de Tom Jobim que lembram algo da claridade matinal de Debussy. Não importando a ordem cronológica em que foram compostas, Estrada do Sol quebra o ciclo de procura e espera que aprisionava Dolores. A sua busca de felicidade significava procurar e encontrar o amor definitivo. Para isso e por isso ela esperava. Em Estrada do Sol a mulher livre sai à vida e resolve o conflito.

A chuva caiu, mas alguns pingos ainda estão a brilhar e dançam alegres ao vento da canção. O barco voltando é a alegria de alguém que esperava. $\mathrm{Na}$ Estrada do Sol não há mais espera. A alegria nasce quando sai de si mesma para ver e caminhar à luz daquele sol.

A vida e a obra de Dolores Duran são de alta voltagem emocional e expressam uma experiência muito particular do feminino que, embora muito marcada pelos valores de uma determinada época, preserva alguns outros essenciais que nos lançam em certas confluências do feminino com o sagrado.

É a história de um percurso, de uma vida breve, em que se misturam experiências e conflitos típicos das circunstancias de um tempo com valores atribuídos ao feminino, tais como o acolhimento, a ternura, a abertura existencial para a escuta e a experiência do amor. Todos os amigos de Dolores dizem que ela não era uma mulher triste e deprimida, como algumas de suas músicas poderiam sugerir, mas há, sem dúvida, um eu poético em conflito com essa pessoa de comportamento livre que circulava na noite de Copacabana na década de 1950

Há o feminino de Maria, da conversa íntima à devoção das multidões. Há o feminino de Dolores, humana e solitária, entre tantos, entre os bares, as boates e os apartamentos. Maria é a mãe de Jesus, intercessora, mediadora, protetora, mãe de todos. Dolores é uma outra espécie de mãe, a que consola os que sofrem as dores do amor não correspondido, do amor que termina, ou do amor que se busca.

Maria, que muitos chamam Virgem, faz milagres. Dolores não os faz, mas nos lembra de que podem existir milagres nas manhãs de sol e nelas, subitamente, pode se revelar algo do sagrado. O milagre de mais um dia, a descoberta da beleza simples, a atenção, a caminhada no tempo presente, aqui e agora, revelados como uma epifania, pela luz do sol após a chuva na noite passada.

$\mathrm{Na}$ década de 1950 o cinema ainda era a grande diversão. As pessoas comentavam os filmes, acompanhavam nas revistas especializadas as vidas dos atores e atrizes, músicas eram lançadas e ganhavam mundo a partir das telas. Às vezes não importavam muito os filmes. As pessoas iam ao cinema como uma atividade social. Namorar, sair de casa, encontrar os amigos, passear, fazer um lanche ou jantar depois 
do cineminha. As músicas tanto podiam estar em um musical, ou em um western. Podiam estar em Cinderela em Paris, com trilha de Gershwin, ou em Johnny Guitar; podiam vir da Broadway, ou das trilhas sonoras originais.

Dolores Duran, como uma mulher de seu tempo, não ficou alheia a isso. É difícil precisar em uma ou outra música influencias diretas desse ou daquele filme. É mais um clima, uma referência. Era difícil, naquela época, ficar alheio ao cinema. O certo é que ir ao cinema ajudou Dolores a aprender várias canções que depois cantava a seu modo, dando-lhes o seu toque pessoal. Também estavam nos filmes os figurinos que davam dicas para que ela fizesse as roupas de crooner e fosse cantar nas boates de Copacabana. Algumas canções gravadas em inglês, pois aquelas que foram cantadas no rádio, na televisão e nas boates se perderam, têm sinais interessantes para compreender um pouco como o cinema influenciou a Dolores cantora. No cinema brasileiro participou de dois filmes em 1957: Rico Ri a Toa, dirigido por Roberto Farias, onde canta com charme e simpatia Tião, um samba de Wilson Batista e Jorge de Castro, e Quem Sabe, Sabe, de Luiz de Barros, cantando Não se Avexe Não, um baião composto por Chico Anísio e sua mãe, Haydée de Paula.

Over the Rainbow e Cry me a River foram gravadas por Dolores em reuniões musicais na casa de amigos e lançadas comercialmente em CD em 2007. My Funny Valentine foi lançada em um disco de 45 rotações em julho de 1958 e gravado na restaurante Michel em São Paulo. Em todas, há o talento notável de uma moça de origem simples, de pouca instrução formal, mas dona de sofisticada intuição musical, capaz de cantar em vários idiomas com perfeição e dar, no caso das canções em inglês reconhecidas por interpretações marcantes, o toque pessoal que só as grandes cantoras sabem dar. Over the Rainbow faz parte da trilha de O Mágico de Oz (The Wizard of Oz), de autoria de Harold Arlen e E.Y. Harburg, cantada por Judy Garland logo no início do filme. Dorothy, a personagem, adolescente inquieta e meio deslocada, vive entre tios idosos e adultos empregados da fazenda, sem crianças ou jovens por perto, canta que talvez em algum lugar além do arco-íris exista um lugar onde possa sonhar e ficar. É inquietante lembrar que o filme foi lançado em 1939, alguns dias antes do início da Segunda Guerra Mundial.

Talvez a percepção desse sentido simbólico da canção tenha sido parte de seu grande sucesso. No CD lançado em 2007, a partir de fitas recuperadas de gravações caseiras, a interpretação de Dolores, dolente e intensa, em algum momento da década de 1950, não tem mais a guerra como referência, mas, sim, o sempre presente anseio humano de que haja um lugar de escape e abrigo das agruras e conflitos do cotidiano. Como toda boa crooner, Dolores canta para quem está próximo, para quem ela vê o rosto. As boates eram pequenas, 80 a 100 pessoas com casa cheia, e isso dava uma proximidade quase física entre a cantora e seus ouvintes. Dolores acentuava isso. No Mágico de Oz, Judy Garland cantava para plateias; Dolores canta para os amigos. Não era a Dorothy ingênua, quase infantil, de Judy Garland. Era o canto de uma mulher de intensa vida amorosa e é isso que ela passa no modo terno 
como canta Over the Rainbow.

Somewhere over the rainbow

Way up high

There's a land that I heard of

Once in a lullaby

Somewhere over the rainbow

Skies are blue

And the dreams that you dare to dream

Really do come true

Someday I'll wish upon a star

And wake up where the clouds are far behind me

Where trouble melts like lemon drops

Away above the chimney tops

That's where you'll find me

Somewhere over the rainbow

Bluebirds fly

Birds fly over the rainbow

Why then, oh, why can't why?

Cry me a River, lançada por Julie London em 1953, foi incluída no filme The Girl Can't Help It (Sabes o que quero) de Frank Tashlin, 1955. A música fez um grande sucesso. Julie, mulher muito bonita e sensual, a cantava em uma sequência quase surreal. Ela surge como um delírio bêbado de Tom Ewell. Aparece em descontinuidade, ora no pé da escada, na porta do quarto, na cama; ora sensual, ora insolente e ameaçadora. E Tom Ewell parece cativo de seu encanto. Na letra está presente algo daquela nova mulher que timidamente começa a surgir nos anos 1950. Ativa, senhora de sua sexualidade, encarando os homens de frente, sem submeter-se aos papéis que lhes eram impostos. É a persona social de Dolores que canta essa canção e não o seu eu poético que parecia às vezes em conflito com ela. Tem mais a ver com a mulher Dolores do que com a compositora Dolores. Ela canta a canção, confiante, altiva, alternando ironia e doçura. É lindo como explora as ambiguidades da letra e como isso é tão próximo de sua vida. Não é possível afirmar se Dolores viu ou não o filme. É provável que sim, pois em tempos sem internet ou DVD, era preciso ir ao cinema e ver os filmes várias vezes se uma cantora quisesse aprender a música e tirar a letra de uma canção. Suas amigas dizem que isso era exatamente o que ela fazia. Inteligente como era, Dolores sempre acrescentava às canções algo que só o cinema era capaz de revelar, algo não evidente, não óbvio, e que ela levava para as canções. 
Now you say you love me

You cried the long night through

Well, you can cry me a river

Cry me a river

I cried a river over you

Now you say you're sorry

For being so untrue

Well, you can me cry me a river

Cry me a river

I cried a river over you

You drove me

Nearly drove me out of my head

While you never shed a tear

Remember?

I remember all that you said

Told me love was too plebeian

Told me you were through with me

Now you say you love me

Well,just to prove you do

Come on and cry me a river

Cry me a river

I cried a river over you

Gravada ao vivo no restaurante Michel em São Paulo e lançada em disco de 45 rotações com quatro músicas, My Funny Valentine é das gravações mais reveladoras dos dons de Dolores como cantora. Acridoce e pungente, ela canta o modo como a vê o homem que esperava. Era assim que muitos de seus namorados e amigos a viam e a queriam bem. Ela não era bonita. Se achava meio gordinha, implicava com seu cabelo e tinha o apelido de "Bochecha". Quando canta "is your figure less than greek/is your mouth a little weak/when you open it to speak/ are you smart", é quase como ela se olhasse no espelho. Tanto Sinatra quanto Chet Baker, ao final pedem, entregues ao sortilégio daquela Valentine, que ela fique. Dolores cantava essa canção como aquilo que gostaria de ouvir. É um efeito cinematográfico potente e de intensa significação poética.

É fascinante perceber a atualidade de Dolores em um tempo de afirmação das mulheres no mundo, a beleza com que expressa seus conflitos, alegrias e anseios, a verdade e a potência de sua obra.

100 ALCEU - v. 18 - n. 36 - p. 91 a 102 - jan-jun./2018 
Fernando Pessoa, se a encontrasse, talvez dissesse:

Sossega, coração! Não desesperes!

Talvez um dia, para além dos dias,

Encontres o que queres por que o queres.

Então, livre de falsas nostalgias,

Atingirás a perfeição de seres.

Mas pobre sonho o que só quer não tê-lo!

Pobre esperança a de existir somente!

Como quem passa a mão pelo cabelo

E em si mesmo se sente diferente,

Como faz mal ao sonho o concebê-lo!

Sossega, coração, contudo!Dorme!

O sossego não quer razão, nem causa.

Quer só a noite plácida e enorme,

A grande, universal, solene pausa

Antes que tudo em tudo se transforme.

Ney Costa Santos

Professor da Pontifícia Universidade Católica do Rio de Janeiro (PUC-Rio)

Doutorando em Comunicação (PUC-Rio)

Recebido em novembro de 2017.

Aprovado em fevereiro de 2018.

\section{Referências}

\section{Livros}

FAOUR, Rodrigo. Dolores Duran: a noite e as canções de uma mulher fascinante. Rio de Janeiro: Record, 2012.

MATOS, Maria Izilda Santos de. Dolores Duran: experiências boêmias em Copacabana nos anos 50. Rio de Janeiro: Bertrand Brasil, 1997.

CRUZ, São João da. Cântico Espiritual e Outros Poemas. Lisboa: Assírio e Alvim,1982. VIANY, Alex. Introdução ao Cinema Brasileiro. Rio de Janeiro. MEC/Instituto Nacional do livro, 1959.

PESSOA, Fernando. Poesias Coligidas. Rio de Janeiro: Nova Fronteira, 1981. 


\section{Músicas}

Estrada do Sol (Antonio Carlos Jobim e Dolores Duran)

A Noite do meu bem (Dolores Duran)

Noite de Paz (Dolores Duran)

Fim de caso (Dolores Duran)

Ideias Erradas (Ribamar e Dolores Duran)

My Funny Valentine ( Richard Rodgers e Lorenz Hart)

Over the Rainbow ( Harold Arlen e Yip Harburg)

Cry me e River ( Arthur Hamilton)

\section{Filmes}

FLEMING, Victor. O Mágico de Oz. Longa metragem, cor. Direção: Victor Fleming. Produção:Mervin Le Roy;Elenco: Judy Garland,Frank Morgan, Ray Bolger, Bert Lahr e Jack Haley; MGM,USA, 1939.

TASHLIN, Frank. Sabes o que Quero (The girl can't help it). Longa metragem, cor: Direção e Produção: Frank Tashlin; Elenco: Tom Ewell, Jayne Mansfield, Edmond O’Brien e Julie London; $20^{\text {th }}$ CENTURY FOX, USA, 1956

SIDNEY, George. Meus Dois carinhos (Pal Joey). Longa metragem, cor. Direção: George Sidney; Elenco: Frank Sinatra, Rita Hayworth, Kim Novak. COLUMBIA PICTURES,USA, 1957.

FARIAS, Roberto. Rico Ri a Toa. Longa metragem, preto e branco. Direção: Roberto Farias; Produção: Murilo Seabra; Elenco: ZéTrindade, Violeta Ferraz, Armando Camargo, Silvinha Chiozzo. BRASIL VITA,Brasil,1957

BARROS de, Luiz. Quem Sabe, Sabe. Longa metragem, preto e branco. Direção: Luiz de Barros; Produção: Osvaldo Massaini e Alípio Ramos; Elenco: Violeta Ferraz, Humberto Catalano, Francisco Dantas. CINEDISTRI.Brasil,1957

\section{Resumo}

O artigo assinala os pontos de contato da obra da cantora e compositora Dolores Duran, tão característica de um tipo de subjetividade dos anos 1950 no Rio de Janeiro, com a poesia, o cinema e o sagrado ao expressar uma mística do cotidiano.

\section{Palavras-chave}

Música. Poesia. Cinema. Religião.

\section{Abstract}

The article notes the points of contact of the work of singer-songwriter Dolores Duran, so characteristic of a kind of subjectivity of the years 1950 in Rio de Janeiro, with poetry, movies and the sacred in expressing a mystique of everyday life.

\section{Keywords}

Music. Poetry. Cinema. Religion 